\title{
The Effect of Milk Replacer Incorporation on the Physicochemical Properties of Milk Chocolate
}

\author{
Saadah M. Saidin*, ${ }^{1}$, Nazaruddin Ramli ${ }^{1}$, Tan Y. Nee ${ }^{2}$ and Md K. Ayob*,1 \\ ${ }^{I}$ School of Chemical Sciences and Food Technology, Faculty of Science and Technology, Universiti Kebangsaan \\ Malaysia, 43600 Bangi, Selangor, Malaysia \\ ${ }^{2}$ Department of Agricultural and Food Science, Faculty of Science, Universiti Tunku Abdul Rahman, Jalan Universiti, \\ Bandar Barat, 31900 Kampar, Perak, Malaysia
}

\begin{abstract}
This study investigated the effect of milk replacer incorporation on the physicochemical properties of milk chocolate. The formulations were developed using Mixture Design of Design Expert ${ }^{\circledR}$ version 6.0. through a binary mixing of skimmed milk powder and milk replacer at following ratios: 100:0, 75:25, 50:50, 25:75 and 0:100. Results demonstrated that milk chocolate which comprised of $100 \%$ milk replacer significantly had the darker colour and more viscous compared to the other milk chocolate samples $(P \leq 0.05)$. On the other hand, the milk chocolate which consisted of $75 \%$ skimmed milk powder and $25 \%$ milk replacer had better resistance to fat bloom formation throughout the 10 weeks of storage at room temperature $\left(25^{\circ} \mathrm{C}\right)$. This study suggested the feasibility of incorporating milk replacer in milk chocolate. The milk chocolate with milk replacer had softer texture and less fat bloom formation compared to the milk chocolate with skimmed milk powder alone.
\end{abstract}

Keywords: Binary mixing, mixture design, milk replacer, physicochemical properties.

\section{INTRODUCTION}

Chocolate is the most craved food probably due to its uniquely attractive taste, positive contribution to human nutrition with the presence of antioxidants, and potential to arouse positive emotions [1,2]. Chocolate is a complex multiphase consists of fine-solid particles from cocoa, sugar and certain milk components in a continuous fat phase (cocoa butter, milk fat and emulsifier). Different forms and flavors of chocolate are produced by varying the quantities of the different ingredients [2,3].

According to Beckett (2000) [4], the presence of milk will give chocolate a creamier and smoother texture. The current techniques for manufacturing chocolate-trade products comprising chocolate or cocoa products, involve partial or full replacement of skimmed milk for costreduction yet not affecting the taste, texture, appearance and nutritional value of the chocolate or cocoa-products. For example, vegetable-based milk derived from peanut, cowpea or soy is used to partially or fully replace the more expensive dairy ingredients, such as skimmed milk powder or sweetened condensed milk. The incorporation of vegetablebased milk powder in milk chocolate was highly accepted by consumers and had the potential to be marketed which in fact helped in lowering chocolate or cocoa products processing cost $[5,6]$.

*Address correspondence to this author at the School of Chemical Sciences and Food Technology, Faculty of Science and Technology, Universiti Kebangsaan Malaysia, 43600 Bangi, Selangor, Malaysia;

Tel: +603-8921-5992; Fax: +603-8921-3232;

E-mails: saamasz84@gmail.com; mkhan@ukm.edu.my
Previous research demonstrated that both maltodextrin and modified starch were able to act as bulking agent [7], fat replacer [8], flavour binder and aroma binder [9]. These ingredients had shown to provide surface sheen, inhibit crystallization [10-12] and were widely used as emulsifiers and thickening agents [13]. All these characters are important in preparing milk chocolate with good physicochemical properties. Therefore, the effects on the physicochemical properties of milk chocolate with partially or fully substituted milk replacer were examined. The milk replacer which consisted of maltodextrin and modified starch-based was applied to substitute skimmed milk powder in milk chocolate.

\section{MATERIALS AND METHODS}

\section{Milk Chocolate Sample Preparation}

The formulations of milk chocolate were developed through a binary mixture of skimmed milk powder and milk replacer using Mixture Design of Design Expert () version 6.0. The formulations of skimmed milk powder and milk replacer in milk chocolate samples were varied with the following ratios:

A: Chocolate sample with $100 \%$ skimmed milk powder

B: Chocolate sample with $100 \%$ milk replacer

C: Chocolate sample with $50 \%$ skimmed milk powder and 50\% milk replacer

D: Chocolate sample with $75 \%$ skimmed milk powder and $25 \%$ milk replacer 
E: Chocolate sample with $25 \%$ skimmed milk powder and $75 \%$ milk replacer

F: Commercial milk chocolate sample from local market (with $100 \%$ full cream milk powder)

The Milk replacer applied for this study comprised of maltodextrin and modified starch as the main constituents. This particular milk replacer was formulated and supplied by Matrix Flavour and Fragrance Pte Ltd. which involved as this project collaborator.

All the ingredients were mixed in a Hobart Mixer with medium blending speed. The milk chocolate samples were refined using a Pascal 3-roll refiner until the particle size reached between 18-35 $\mu \mathrm{m}$, followed by conching process for at least four (4) hours at $60^{\circ} \mathrm{C}$. Subsequently, the milk chocolate mixture was tempered at approximately $34^{\circ} \mathrm{C}$ using a tabletop tempering machine. Then, the tempered chocolate was poured into a mold and kept cool at $15^{\circ} \mathrm{C}$ for three (3) hours. The physicochemical properties of milk chocolate samples were determined and compared. The full formulations of milk chocolate for all studied samples were presented in Table $\mathbf{1}$.

\section{Physicochemical Properties Analysis}

\section{Colour}

The colour of each milk chocolate samples was analyzed using a Minolta Chromameter (model CR 300, Stifflers Surplus Inc., Phoenix, AZ, USA) with the Commission Internationale de I'Eclairage (CIE) colour system in which colour was expressed in $L^{*}, a^{*}$ and $b^{*}$, where $L^{*}$ defined as lightness, $a^{*}$ denotes the red/green value and $b^{*}$ the yellow/blue value [14]. Results were expressed as means of three measurements. Commercial milk chocolate was functioned as control in this analysis.

\section{Hardness}

The hardness of milk chocolate was measured using a Texture Analyzer (Model Shimadzu AGS-J 500N, Shimadzu Inc., Chiyoda-ku, Tokyo, Japan). A stainless steel needle (no. TA9) with a diameter of $1.5 \mathrm{~mm}$ and length of $46 \mathrm{~mm}$ penetrated $1 \mathrm{~mm}$ into the samples at the rate of $60 \mathrm{~mm} / \mathrm{min}$. The hardness of each milk chocolate samples was measured at eight different fields of the same sample. The results were expressed as mean values [15]. Commercial milk chocolate was included as control for this analysis.

\section{Viscosity Measurement}

\section{Viscometer}

Viscosities of the milk chocolate samples were measured using a Brookfield Digital Viscometer (Model DV-II; Brookfield Engineering Laboratories, Middleboro, MA, USA) coupled with a disc spindle (no.7) at $20 \mathrm{rpm}$. Each milk chocolate samples was incubated at $38^{\circ} \mathrm{C}$ for one (1) hour prior to analysis. The viscosity reading was taken when the centipoise unit (cps) showed constant. The viscosity measurement using viscometer was compared with the results obtained using rheometer. Commercial milk chocolate functioned as control in this analysis.

\section{Rheometer}

The viscosities of the milk chocolate samples were also measured using rheometer (Model Physica MCR301, Anton Paar Germany GmbH, Ostfildern, Germany). The specimens were placed between a cone and a flat plate. Viscosity measurements using rheometer were conducted according to the method of Aeschlimann and Beckett (2000); and Radosavljevic (2000) [16, 17]. The plate geometry was preheated to $40^{\circ} \mathrm{C}$ prior to analysis. Flow curve were generated by increasing the shear rate from $2 \mathrm{~s}^{-1}$ to $50 \mathrm{~s}^{-1}$ in 3 min ("Ramp up" step), followed by maintaining the high shear rate of $50 \mathrm{~s}^{-1}$ for $1 \mathrm{~min}$. The shear rate was then decreased from $50 \mathrm{~s}^{-1}$ to $2 \mathrm{~s}^{-1}$ in $3 \mathrm{~min}$ ("Ramp down" step). The flow curves of shear stress against shear rate were obtained thereafter. Commercial milk chocolate was functioned as control for this analysis.

\section{Bloom Stability Analysis}

Bloom formation analysis of milk chocolates was carried out according to the method described by Sabariah et al. (1998) [18] where scores were given based on visual observations: $5=$ excellent (glossy and without bloom); $4=$ good (slightly dull and without bloom); 3 = fair (dull surface and without bloom); 2 = acceptable (bloom detected); $1=$ unacceptable (complete bloom). Bloom formations of milk

Table 1. Milk Chocolate Formulationss with different ratio of Skimmed Milk Powder and Milk replacer.

\begin{tabular}{|c|c|c|c|c|c|}
\hline Ingredients/Samples Code & $\mathbf{A}$ & B & $\mathbf{C}$ & D & $\mathbf{E}$ \\
\hline Milk replacer & 0.00 & 15.00 & 7.5 & 3.75 & 11.25 \\
\hline Cocoa Butter Substitute & 33.75 & 33.75 & 33.75 & 33.75 & 33.75 \\
\hline Lecithin & 0.48 & 0.48 & 0.48 & 0.48 & 0.48 \\
\hline Vanilla & 0.02 & 0.02 & 0.02 & 0.02 & 0.02 \\
\hline Total & 100.00 & 100.00 & 100.00 & 100.00 & 100.00 \\
\hline
\end{tabular}


chocolates were monitored throughout 10 weeks of storage (one week intervals) at $15{ }^{\circ} \mathrm{C}$, room temperature $\left(25^{\circ} \mathrm{C}\right)$ and $50 \%$ relative humidity respectively. Commercial milk chocolate was included as control.

\section{Scanning Electron Microscopy (SEM) Observation}

The microstructural study of milk replacer incorporated milk chocolate was conducted using SEM (LEO 1450VP, UK). Microstructure of the milk chocolate samples were observed at magnification $\times 500$ and $\times 1000$. Surface morphology of commercial milk chocolate and identical milk-flavoured powder incorporated milk chocolate were compared [19].

\section{Statistical Analysis}

Reported data represent the mean of three measurements in each experiment. Statistical Analysis Systems software version 6.12 (SAS Institute, Cary, NC, USA) was used for analysis of variance. Values of $P \leq 0.05$ were considered to be significant [20].

\section{RESULTS AND DISCUSSIONS}

\section{Physicochemical Properties Analysis}

\section{Colour}

Results demonstrated that milk chocolate with $100 \%$ skimmed milk powder and milk chocolate with 50\% skimmed milk powder and $50 \%$ milk replacer significantly $(P \leq 0.05)$ showed highest lightness value (49.25) and (48.38) respectively compared to other milk chocolates. Lowest lightness value (43.75) was shown in milk chocolate with $100 \%$ milk replacer. As seen in Table 2, milk chocolate with $100 \%$ skimmed milk powder demonstrated significantly $(P \leq 0.05)$ greater intensities in redness and yellowness value compared to milk chocolate with $100 \%$ milk replacer incorporation as indicated by higher value of $a^{*}$ and $b^{*}$. The lightness and colour variation between milk chocolate with $100 \%$ skimmed milk powder and milk chocolate with $100 \%$ milk replacer probably attributed to the occurrence of nonenzymatic browning reaction (Maillard reaction) between reducing sugars and amino acids in the milk chocolate with $100 \%$ skimmed milk powder [5]. Hence, the milk chocolate with $100 \%$ skimmed milk powder exhibited higher intensities of lightness and redness compared to milk chocolate with $100 \%$ milk replacer. As a comparison, commercial milk chocolate tends to had lower lightness value as compared to milk chocolate with $100 \%$ skimmed milk powder or $100 \%$ milk replacer. However, commercial milk chocolate showed significantly highest yellowness intensity (3.62) compared to other milk chocolate samples $(P \leq 0.05)$ (Table 2).

\section{Hardness}

Hardness of the milk chocolates were measured and expressed as the force in ' $\mathrm{gf}$ ' unit needed to penetrate the samples. As seen in Table 2, sample A, milk chocolate with $100 \%$ skimmed milk powder exhibited significantly greatest hardness among the milk chocolate samples $(P<0.05)$. Supposedly, milk chocolates tend to had softer texture than the other variety of chocolates due to the diluting effect of milk fat on cocoa butter. Nevertheless, higher hardness $\left(149.26 \times 10^{3} \mathrm{gf}\right)$ was shown in milk chocolate with $100 \%$ skimmed milk powder than expected.

This circumstance probably attributed to the great decrease of milk fat in skimmed milk powder which eventually increased the hardness of the milk chocolate product. On the other hand, the commercial milk chocolate which should be more than $26 \%$ fat according to Malaysian Food Regulation (1985) [21], exhibited the softest texture compared to the other milk chocolate samples.

\section{Viscosity}

By referring to Table 2, the commercial sample had the highest viscosity $\left(2.75 \times 10^{4} \mathrm{cps}\right)$, which was significantly different $(p<0.05)$ from the other samples $(p<0.05)$. This might be due to better refining and conching process technologies found in the commercial chocolate factory, and the commercial sample also had the finest particle size that affected the final chocolate viscosity. The B and E samples, which had the high percentage of milk replacer, had higher viscosities $\left(2.33 \times 10^{4} \mathrm{cP}\right.$ and $2.27 \times 10^{4} \mathrm{cP}$, respectively).

Table 2. Physical properties of compound milk chocolate.

\begin{tabular}{|c|c|c|c|c|c|c|}
\hline \multirow{2}{*}{ Physical Properties } & & & & Sample & & \\
\hline & $\mathbf{A}$ & B & C & D & $\mathbf{E}$ & $\mathbf{F}$ \\
\hline $\mathrm{L}^{*}$ & $49.25^{\mathrm{a}}$ & $43.75^{\mathrm{c}}$ & $48.38^{\mathrm{a}}$ & $46.69^{\mathrm{b}}$ & $46.67^{\mathrm{b}}$ & $46.58^{\mathrm{b}}$ \\
\hline$a^{*}$ & $10.47^{\mathrm{a}}$ & $7.13^{\mathrm{c}}$ & $9.08^{\mathrm{b}}$ & $8.34^{\mathrm{b}}$ & $5.94^{\mathrm{d}}$ & $8.33^{\mathrm{b}}$ \\
\hline$b^{*}$ & $1.78^{\mathrm{b}}$ & $0.32^{\mathrm{c}}$ & $1.08^{\mathrm{bc}}$ & $1.9^{\mathrm{b}}$ & $0.12^{\mathrm{c}}$ & $3.62^{\mathrm{a}}$ \\
\hline $\begin{array}{l}\text { Hardness } \\
\left(\mathrm{x} 10^{3} \mathrm{gf}\right)\end{array}$ & $149.26^{\mathrm{a}}$ & $119.69^{\mathrm{b}}$ & $63.99^{\mathrm{d}}$ & $76.6^{\mathrm{c}}$ & $61.31^{\mathrm{d}}$ & $61.18^{\mathrm{c}}$ \\
\hline $\begin{array}{l}\text { Viscosity } \\
\left(\mathrm{x} 10^{4} \mathrm{cps}\right)\end{array}$ & $1.67^{\mathrm{c}}$ & $2.33^{\mathrm{b}}$ & $1.57^{\mathrm{c}}$ & $1.67^{\mathrm{c}}$ & $2.27^{\mathrm{b}}$ & $2.75^{\mathrm{a}}$ \\
\hline Viscosity (Pa.s) & 167 & 233 & 157 & 167 & 227 & 275 \\
\hline
\end{tabular}

a different alphabet in a same row shows no significant value at $\mathrm{P} \geq 0.05$ 
These higher viscosities might be due to the presence of maltodextrin and modified starch that had been widely used as thickening agents and emulsifiers to increase viscosity and mouthfeel [11]. Samples A and D, which had high contents of skimmed milk powder, had the same viscosity value of $1.67 \times 10^{4} \mathrm{cP}$. These viscosity results were not significantly different $(p \geq 0.05)$ from the viscosity of sample $C$ that had a slightly lower value $\left(1.57 \times 10^{4} \mathrm{cP}\right)$. These results suggested that the presence of maltodextrin and modified starch in the milk replacer helped to increase the viscosity and mouthfeel of the chocolate [11].

However, the Brookfield viscometer measures viscosity by only generating numbers and results that pertain to the product or process without a concern of the rheological theory. Brookfield viscometers do not directly define shear rates and absolute viscosities for non-Newtonian fluids, and the viscometers require equipment with defined geometries and accurate temperature control for all measurement parameters, particularly shear rate and shear stress. Therefore, rheometer was applied to complete the viscosity measurements of these samples.

\section{International Office of Cocoa, Chocolate and Sugar Confectionery (IOCCC) 2000}

\section{Method (IOCCC 2000), Using a Rheometer}

The rheometer measurement is based on rheological behaviour, and it requires all measurement parameters, particularly shear rate and shear stress. According to Servais et al. (2003) [22], an increase in the shear rate disrupts the aggregates of particles in molten chocolate causing a diminished size and decreasing the viscosity to an equilibrium value. If the shear rate is reduced, the aggregates will reform and the viscosity will get back to a higher equilibrium value [23]. The formation and disruption rates of aggregates are influenced by shear stress and interaction energy [23]. The stress in the chocolate particles is derived from the particle-particle interaction, the amount and specific surface area of the particles and the effects of emulsifiers and moisture $[24,25]$. When the measurement was carried out, the cone or bob put a pressure or stress on the sample that weakened the particle interaction in the chocolate system and diminished the surface area of the interacted particles. This reduced the apparent viscosity of the chocolate samples until

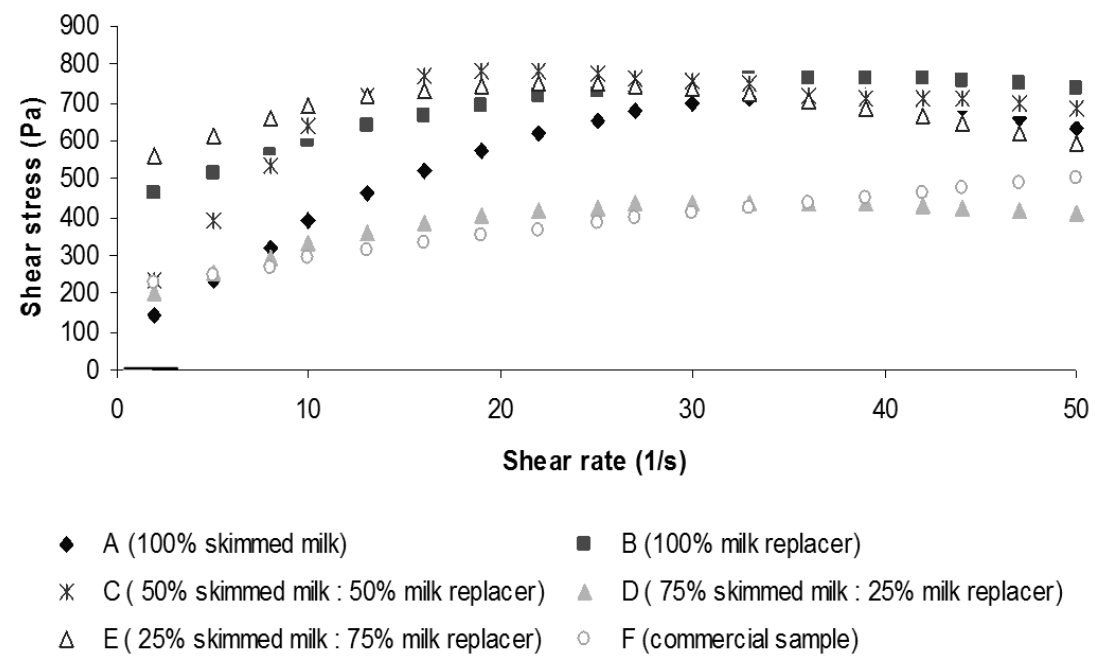

Fig. (1a). Relationship between the shear rate and shear stress of the samples during ramp up.

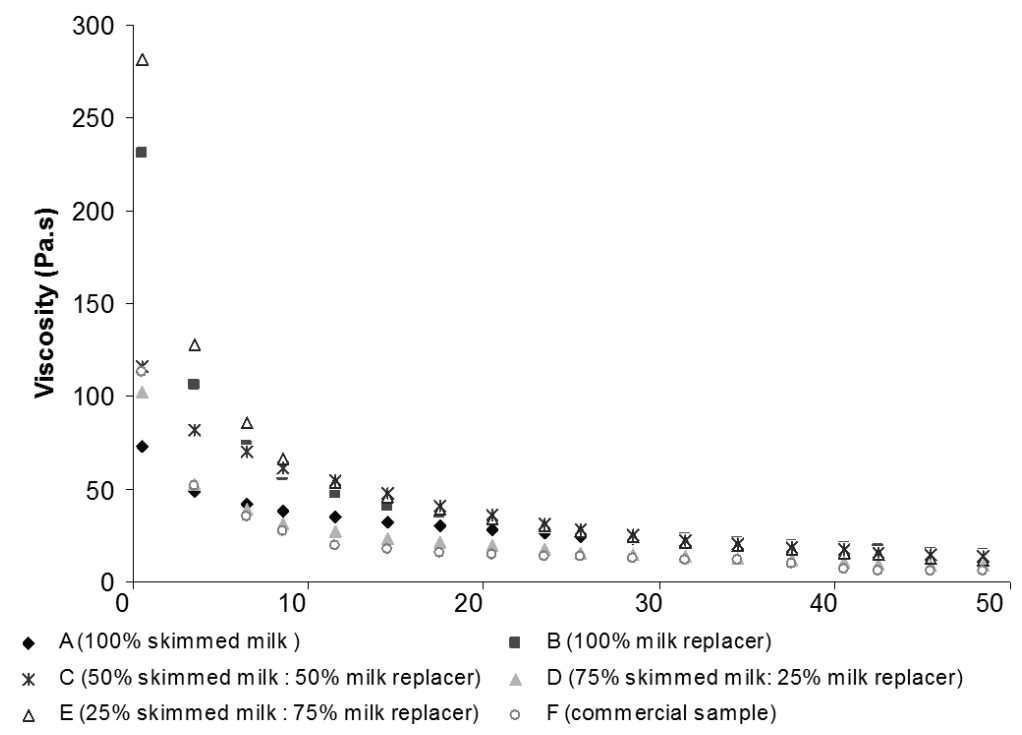

Fig. (1b). Relationship between the viscosity and shear stress of the samples during ramp up. 
they achieved an equilibrium state. This phenomenon was investigated on the chocolate samples with the formulations using binary mixtures of skimmed milk powder and milk replacer. The viscosity of these samples was measured as previously described $[16,26]$ with the measuring temperature at $40^{\circ} \mathrm{C}$. The shear rate, shear stress and viscosity of the particle interactions in this study are shown in Fig. (1a) through Fig. (2b).

Figs. (1a and 1b) showed that the shear stress of each sample increased, but the viscosity of each sample decreased as the shear rate increased from $2 \mathrm{~s}^{-1}$ until $50 \mathrm{~s}^{-1}$ (Ramp up). This occurred due to the increasing stress on the samples by the faster movements of the plate geometry per second. The stress between the cone and the plate initiated flow of the sample, and this condition was known as yield stress. It weakened the particle interactions in the chocolate system and deforms the aggregates, which decreased the viscosity of the samples until equilibrium state were reached. Based on Fig. (1b), the initial viscosity for each sample differed based on the milk content in the formulations. The samples with higher contents of milk replacer had higher viscosities than the samples with a high content of skimmed milk powder. At the initial shear rate of $2 \mathrm{~s}^{-1}$, the viscosities of samples B and
E were 231.3 Pa.s and 281.4 Pa.s, respectively. These values were significantly different from the initial viscosities of samples A, C and D (72.8 Pa.s, 116 Pa.s and 102.2 Pa.s, respectively). The initial viscosity of sample $\mathrm{C}$ was close to the viscosity of the commercial sample (116 Pa.s and 113.35 Pa.s, respectively) at the shear rate of $2 \mathrm{~s}^{-1}$. However, as the shear rate increased to $50 \mathrm{~s}^{-1}$, the viscosity for the samples fell within the range of 8.34 Pa.s to 14.77 Pa.s.

The rheological behaviour of the samples during the ramp down was illustrated in Figs. (2a and $\mathbf{2 b}$ ). The shear stress was reduced as the shear rate was decreased from $50 \mathrm{~s}^{1}$ to $2 \mathrm{~s}^{-1}$. The stress on the particular sample was reduced when the speed of the plate geometry was reduced, which weakened the forces that caused yield stress and strengthened the interaction between particles in the system. Hence, the aggregates slowly reformed and the viscosity relaxed back to a higher equilibrium value [23]. Fig. (2b) demonstrated that the initial viscosity for all the samples fell within the range of 5.67 Pa.s. to 12.9 Pa.s. As the shear rate and shear stress decreased, the viscosity slowly increased to complete the aggregation of particles in the chocolate system until they reached the final viscosity with the range of 18.8 Pa.s. to $48 \mathrm{~Pa}$.s, and the highest value was found in sample

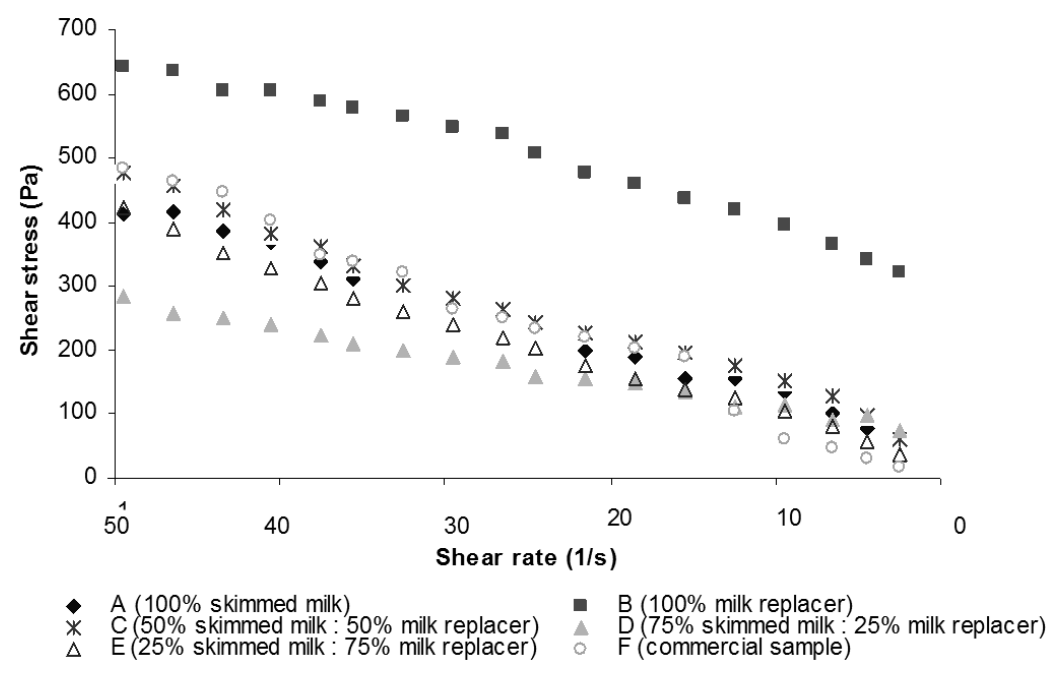

Fig. (2a). Relationship between the shear rate and shear stress of the samples during ramp down.
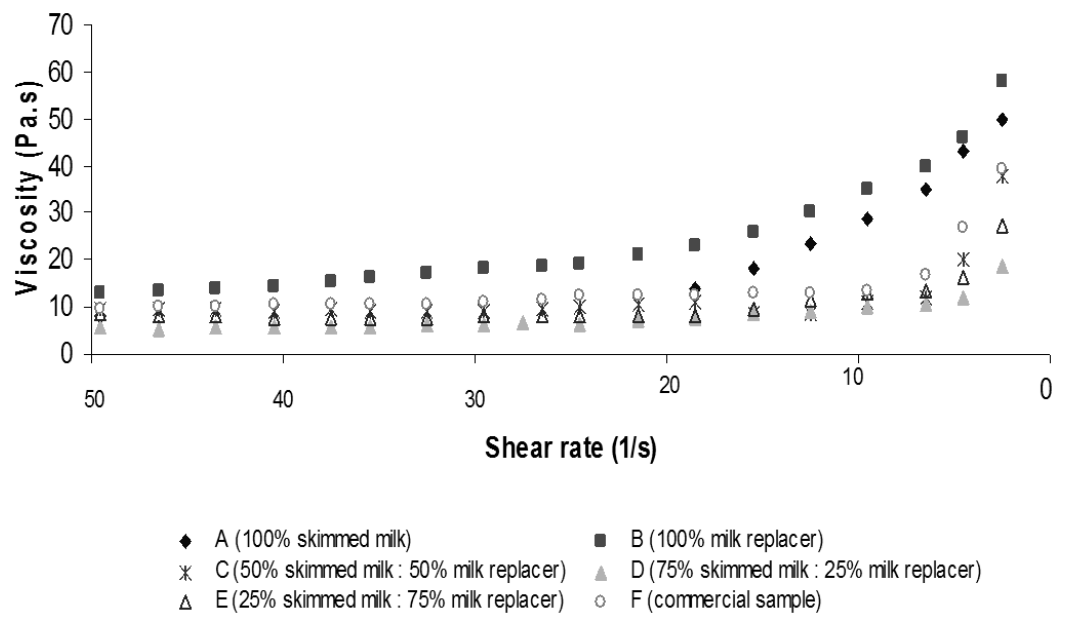

Fig. (2b). Relationship between the viscosity and shear stress of the samples during ramp down. 
B. This was probably due to the presence of large amounts of maltodextrin and modified starch that helped to improve the viscosity of the chocolate [13]. The results also indicated that the compound milk chocolate using 50\% each of skimmed milk powder and identical milk flavoured powder (sample C) had the closest viscosity to the commercial sample (9.54 Pa.s and 9.64 Pa.s., respectively) at the shear rate of $2 \mathrm{~s}^{-1}$. At the shear rate of $50 \mathrm{~s}^{-1}$ the final viscosity of both samples reached 38 Pa.s. and 39.16 Pa.s., respectively. However, the value of the final viscosity was lower than the initial viscosity before the measurement was carried out. This was due to the interference of the chocolate's internal system including hydrodynamic, gravitational and Brownian forces as well as the interaction energy between the particles after the ramp up state.

\section{Fat Bloom Formation on Chocolate Surface}

The formation of white spots on the surface of the chocolate, known as bloom, had become an issue since the cocoa industry began to grow. There are two types of bloom that usually occur after long term storage. Sugar bloom, is a result of crystallization of sugar particles due to evaporation of moisture if kept in damp condition or using hygroscopic ingredients causing a dusty layer on the chocolate surface [27]. While fat bloom is the result of transition of fat in chocolate to the surface, forming a moldy-like white coating on the chocolate $[28,13,29]$. Both of these will limit the shelf life as well as affect the quality of chocolates. The formation of fat bloom is also due to unstable fat and fat modifications. For example, vegetable or milk fat was used to partially or fully substitute cocoa butter in chocolate [4], and these substitutions caused fat bloom that affected the quality and/or appearance of the chocolate by appearing as mold growth. The fat bloom formation on the chocolate surface was observed on each sample at three separate conditions $15^{\circ} \mathrm{C}, 25^{\circ} \mathrm{C}$ or $50 \%$ relative humidity (RH) for ten weeks as shown in Table $\mathbf{3 a}$ to Table $\mathbf{3 c}$.

Table 3a demonstrated that the chocolate samples were more prone to fat bloom at $15^{\circ} \mathrm{C}$ than at the other conditions. If rapid cooling occurred after the tempering process, incomplete fat crystallization might occur to form unstable $\beta$ polymorphs, and fat bloom appeared if uneven migration of the fat took place. The results indicated that the commercial sample was stable without fat bloom throughout the ten weeks of storage. Sample B followed with blooms appeared on the tenth week. However, if the samples were kept at room temperature $\left(25^{\circ} \mathrm{C}\right)$, the temperature alone was insufficient to crystallize the fat in the chocolate preventing the fat from rapidly migrating to the surface. The commercial sample remained glossy within the ten weeks of storage (Table 3b). There was no fat bloom formation on the surface of sample D throughout the storage test, followed by samples B and E, which retained their glossiness until approximately nine weeks. These data suggested that maltodextrin present in the milk replacer was able to retard fat crystallization $[10,11,12]$. However, the consumption of full cream milk powder that contains more milk fat maintains the stable polymorph form type $\mathrm{V}$, for a longer time [4].

Table $3 \mathbf{c}$ included the condition of the samples kept in a humidity chamber with $50 \% \mathrm{RH}$. The results illustrated that the formulations in both the commercial sample and sample $\mathrm{C}$ reduced the formation of fat bloom. In contrast, the surface of the other samples gradually became dull at the beginning of the sixth week. Further, the bloom that formed on the surface of the samples in this condition also involved sugar bloom. The presence of sugar bloom was detected and differentiated from fat bloom by the formation of a white coarse surface instead of just white spots. The condition of $50 \% \mathrm{RH}$ caused the surface of the samples to become damp and the sugar inside the chocolate to melt. The melted sugar was then recrystallized and migrated to the surface. Sugar bloom appears if the temperature of the surface is low and the damp surface is dried out [30].

\section{Determination of Surface Structure}

The difference in particle distribution in the chocolate samples affected by the ingredients used was observed by Scanning Electron Microscopy (SEM). Three samples were selected for the analysis of the effect of different types of cocoa butter substitute and milk used. The samples utilized were the following: a commercial sample that contained commercial cocoa butter substitute (Illepe and Shea fat) and full cream milk powder, sample A that had $100 \%$ of Palm Mid Fraction (PMF) as cocoa butter substitute and skimmed milk powder and sample B that contained newly developed cocoa butter substitute (75\% Palm Mid Fraction and 25\% Rice Bran Oil) and Identical Milk Flavor Powder (Milk Replacer). The results of the SEM micrograph at magnification $500 \mathrm{X}$ for each sample are shown in Figs. (3a, 3c and 3e), and the SEM micrograph results at $1000 \mathrm{X}$ are illustrated in Figs. (3b, 3d and 3f).

Chocolate basically consists of sucrose, milk and cocoa mass coated with fat, such as cocoa butter and a compatible vegetable fat. According to Servais et al. (2004) [21], the sucrose particles had hydrophilic surfaces that interact with the milk particles, cocoa particles and with each other. Figs. (3a to 3f) showed the solid particles in a distinct fat phase on the surface of the chocolate samples. The surface structure of the commercial sample had a smooth surface area with large pores Figs. (3a and $\mathbf{3 b}$ ). This may be due to the commercial sample containing full cream milk powder with bound fat that is difficult to react with commercial cocoa butter substitute and other particles. Thus, it results in a lower content of free fat that forms smooth structures with a refined solid particle distribution on the sample surface [4]. Sample A, which contained skimmed milk powder, had a smoother surface without large pores as compared to the commercial sample Figs. (3c and 3d). The skimmed milk powder had more free fat to interact with hydrophilic sucrose and cocoa particles [4] and a lower fat immobilization [31]. Therefore, it would assist the Palm Mid Fraction fat to obtain a higher fat portion that acted as a lubricant in a continuous phase so as to achieve a smoother surface texture and better flow properties of the chocolate. However, there were 
Table 3a. Fat bloom formation on compound milk chocolate during storage at $15^{\circ} \mathrm{C}$.

\begin{tabular}{|c|c|c|c|c|c|c|c|c|c|c|}
\hline \multirow{2}{*}{ Samples* } & \multicolumn{10}{|c|}{ Weeks } \\
\hline & 1 & 2 & 3 & 4 & 5 & 6 & 7 & 8 & 9 & 10 \\
\hline A & 5 & 5 & 4 & 4 & 3 & 3 & 3 & 3 & 2 & 2 \\
\hline B & 5 & 5 & 4 & 4 & 4 & 4 & 4 & 3 & 3 & 2 \\
\hline $\mathrm{C}$ & 5 & 5 & 4 & 4 & 4 & 4 & 3 & 3 & 2 & 2 \\
\hline $\mathrm{D}$ & 5 & 4 & 4 & 4 & 4 & 3 & 3 & 3 & 2 & 2 \\
\hline E & 5 & 4 & 4 & 4 & 4 & 4 & 4 & 3 & 2 & 2 \\
\hline $\mathrm{F}$ & 5 & 5 & 5 & 5 & 5 & 5 & 4 & 4 & 4 & 4 \\
\hline
\end{tabular}

Table 3b. Fat bloom formation on compound milk chocolate during storage at room temperature $\left(25^{\circ} \mathrm{C}\right)$.

\begin{tabular}{|c|c|c|c|c|c|c|c|c|c|c|}
\hline Samples* & \multicolumn{10}{|c|}{ Weeks } \\
\hline B & 5 & 5 & 5 & 4 & 4 & 4 & 4 & 4 & 4 & 3 \\
\hline $\mathrm{C}$ & 5 & 5 & 5 & 4 & 4 & 4 & 4 & 4 & 3 & 3 \\
\hline $\mathrm{E}$ & 5 & 4 & 4 & 4 & 4 & 4 & 4 & 4 & 4 & 3 \\
\hline $\mathrm{F}$ & 5 & 5 & 5 & 5 & 5 & 5 & 5 & 5 & 5 & 5 \\
\hline
\end{tabular}

Table 3c. Fat bloom formation on compound milk chocolate during storage at $50 \%$ relative humidity.

\begin{tabular}{|c|c|c|c|c|c|c|c|c|c|c|}
\hline \multirow{2}{*}{ Samples* } & \multicolumn{10}{|c|}{ Weeks } \\
\hline & 1 & 2 & 3 & 4 & 5 & 6 & 7 & 8 & 9 & 10 \\
\hline A & 5 & 5 & 4 & 4 & 4 & 3 & 3 & 3 & 3 & 3 \\
\hline B & 5 & 5 & 5 & 5 & 4 & 4 & 3 & 3 & 3 & 3 \\
\hline $\mathrm{C}$ & 5 & 5 & 5 & 5 & 4 & 4 & 4 & 4 & 4 & 4 \\
\hline $\mathrm{D}$ & 5 & 5 & 4 & 4 & 4 & 3 & 3 & 3 & 3 & 3 \\
\hline E & 5 & 5 & 5 & 5 & 4 & 4 & 4 & 4 & 3 & 3 \\
\hline $\mathrm{F}$ & 5 & 5 & 5 & 5 & 5 & 5 & 5 & 5 & 5 & 5 \\
\hline
\end{tabular}

* 5 = excellent (glossy and without bloom); 4 = good (slightly dull and without bloom); 3 = fair (surface becomes dull and without bloom); $2=$ acceptable (bloom detected); 1 = unacceptable (complete bloom).

\begin{tabular}{|c|l|}
\hline A: & Chocolate sample with $100 \%$ skimmed milk powder \\
\hline B: & Chocolate sample with $100 \%$ milk replacer \\
\hline C: & Chocolate sample with $50 \%$ skimmed milk powder and $50 \%$ milk replacer \\
\hline D: & Chocolate sample with $75 \%$ skimmed milk powder and $25 \%$ milk replacer \\
\hline E: & Chocolate sample with $25 \%$ skimmed milk powder and $75 \%$ milk replacer \\
\hline F: & Commercial sample \\
\hline
\end{tabular}

noticeable textures on the surface that were coarse, which might indicate that some solid particles were not completely refined. Thus, longer and better refining and conching processes may be required for a smoother surface texture. 


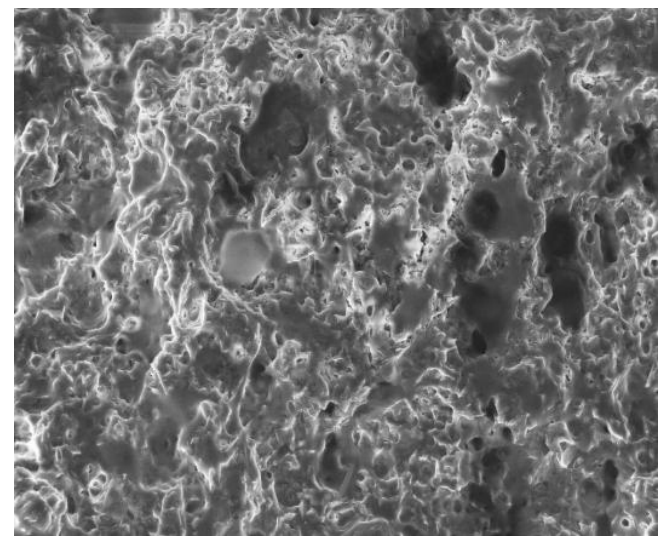

a

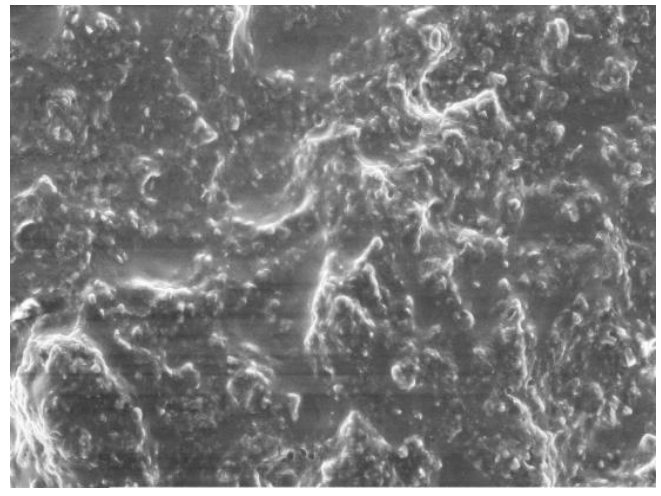

C

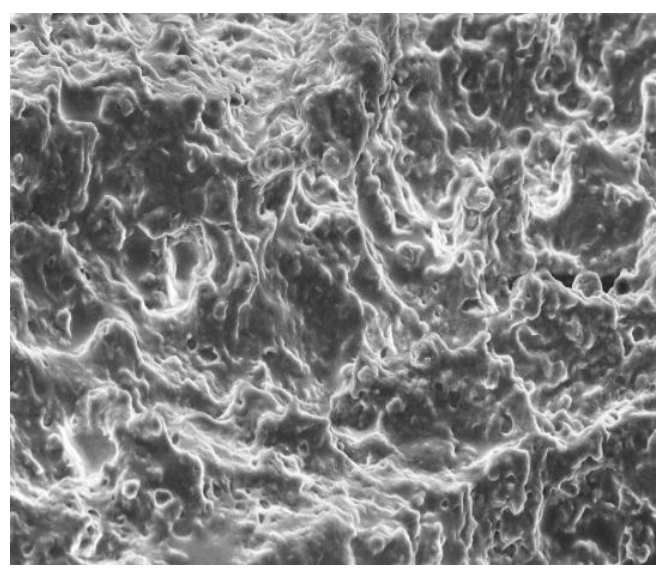

e

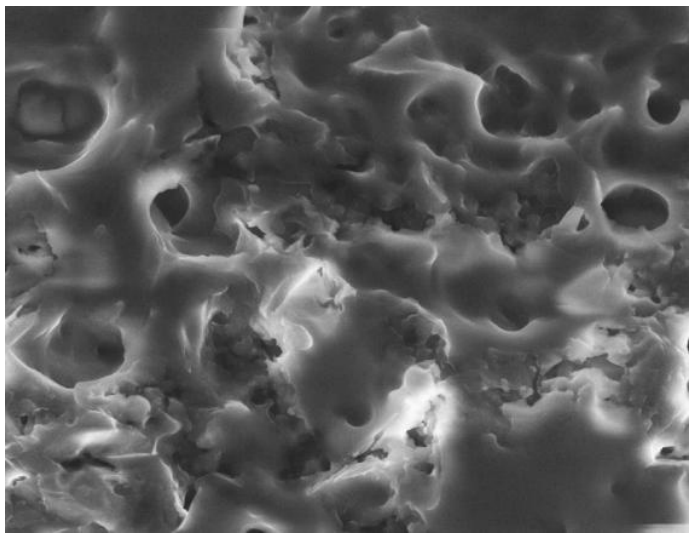

b

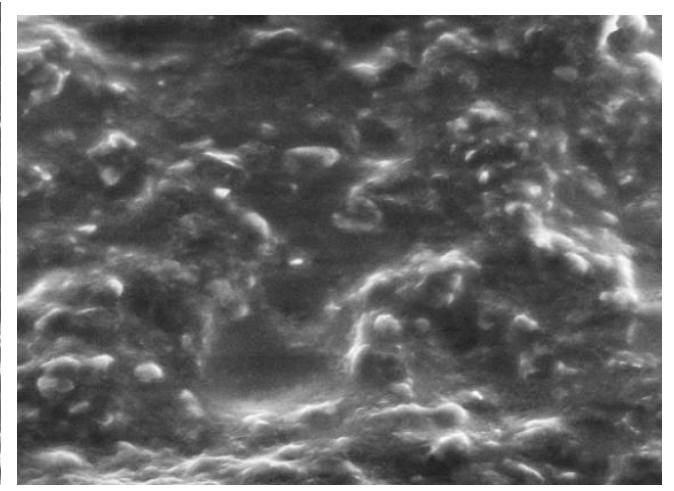

d

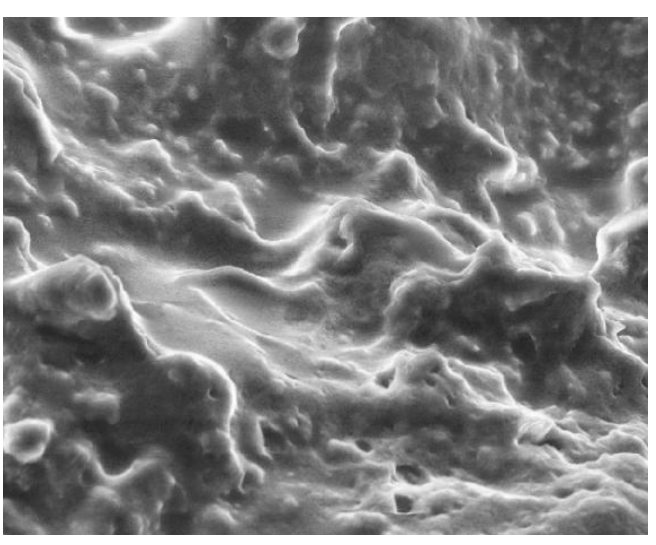

$\mathrm{f}$

Fig. (3). The SEM of surface structure of chocolate samples at 500X magnification (a, $\mathbf{c}$ and $\mathbf{e})$ and at $1000 \mathrm{X}$ magnification (b, $\mathbf{d}$ and $\mathbf{f})$. a-b: Commercial chocolate sample, c-d: Sample A, e-f: Sample B

The surface structure of sample B was glossier than either the commercial sample or sample A Fig. (3e and $\mathbf{3 f}$ ). Therefore, the usage of identical milk flavor powder that contained maltodextrin gave the surface a sheen and inhibited crystallization of fat and sugar [10-12] to delay the formation of fat and sugar bloom. A better refining process would also improve the surface structure as it facilitated the decrease in particle size until the particle distribution of the ingredients coated with fat decreased during the conching process [23].

\section{CONCLUSION}

These results demonstrate that the chocolate formulations using $100 \%$ milk replacer had the darkest colour and highest viscosity with a significant difference from the other samples ( $\mathrm{p} \leq 0.05$ ). Furthermore, the compound chocolate with a binary mixture of $75 \%$ skimmed milk powder: $25 \%$ milk replacer powder had a better resistance to fat bloom at ten weeks of storage at room temperature $\left(25^{\circ} \mathrm{C}\right)$. Together, these results indicate that the utilization of this particular milk replacer in producing milk chocolate helps to improve 
certain physical properties. In terms of surface texture and glossiness, the milk chocolate with milk replacer had better characteristics than the milk chocolate using skimmed milk powder alone.

\section{CONFLICT OF INTEREST}

The authors confirm that this article content has no conflict of interest.

\section{ACKNOWLEDGEMENTS}

The authors would like to express their gratitudes to the Universiti Kebangsaan Malaysia for supporting this effort through the Research University Grant of UKM-GUP-BTK08-14-304 as well as the School of Chemical Sciences and Food Technology, Faculty of Science and Technology, Universiti Kebangsaan Malaysia.

\section{REFERENCES}

[1] Afoakwa EO, Paterson A, Fowler M. Factors influencing rheological and textural qualities in chocolate - a review. Trends in Food Sci Technol 2007; 18: 290-8.

[2] El-Kalyoubi M, Khallaf MF, Abdelrashid A, Mostafa EM. Quality characteristics of chocolate - containing some fat replacer. Ann Agri Sci 2011; 56(2): 89-96.

[3] Foong YJ, Lee ST, Ramli N, Tan YN, and MK Ayob. Incorporation of potential probiotic lactobacillus plantarum isolated from fermented cocoa beans into dark chocolate: bacterial viability and physicochemical properties analysis: Incorporation of Probiotic into Dark Chocolate. J Food Qual 2013; 36 (3): 164-71.

[4] Beckett ST. The Science of Chocolate. RSC Paperbacks, U.K. 2000.

[5] Aidoo H, Sakyi-Dawson E, Tano-Debrah K, Saalia, F.K. Development and characterization of dehydrated peanut-cowpea milk powder for use as a dairy milk substitute in chocolate manufacture. Food Res Int 2010; 43: 79-85.

[6] Deshpande RP, Chinnan MS, Mcwatters KH. Optimization of a chocolate-flavoured, peanut-soy beverage using response surface methodology (RSM) as applied to consumer acceptability data. LWT-Food Sci Technol 2008; 41: 1485-92.

[7] Sadeghi A, Shahidi F, Mortazavi SA, Mahalati MN. Evaluation of different parameters on maltodekstrin production by -amylase Termamyl2-x. World App Sci J 2008; 3(1): 34-9.

[8] Alexander RJ. Maltodextrins: Production, properties, and applications. In: Schenck FW, Hebeba RE, Eds. Starch Hydrolysis Products: Worldwide Technology, Production, application. New York: VCH Pulishers, 1992; pp. 233-75.

[9] Misharina TA, Terenina MB, Krikunova NI. Retention of components in a mixture of volatile organic substances by maltodextrins. App Biochem Microbiol 2008; 44(3): 328-31.

[10] Chronakis IS. On the molecular characteristics, compositional properties, and structural-functional mechanisms of maltodextrins: A review. Crit Rev Food Sci Nutr 1998; 38(7): 599-637.
[11] Dokic-Baucal L, Dokic P, Jakovljevic J. Influence of different maltodextrins on properties of $\mathrm{O} / \mathrm{W}$ emulsions. Food Hydrocoll 2004; 18(2): 233-9.

[12] Setser CS, Racette WL. Macromolecule replacers in food products. Crit. Rev. Food Sci Nutr 1992; 32: 275.

[13] Karnjanolarn R, Mccarthy KL. Rheology of different formulationss of milk chocolate and the effect on coating thickness. J Texture Stud 2006; 37(6): 668-80.

[14] Rossini K, Norena CPZ, and Brandelli A. Changes in the color of white chocolate during storage: potential roles of lipid oxidation and non-enzymatic browning reactions. J Food Sci Technol 2011; 48(3): 305-11.

[15] Ramli N, Rahman SA. Koko Dan Coklat, Sumber, Pemprosesan, Nilai Pemakanan. Dewan Bahada dan Pustaka, 2005.

[16] Aeschlimann JM, Beckett ST. International inter-laboratory trials to determine the factors affecting the measurement of chocolate viscosity. J Texture Stud 2000; 31(5): 541-76.

[17] Radosavljevic S, Achlunk A. 2000. Melting Chocolate. Sydney: CRC for Polymers 2000.

[18] Sabariah S, Ali ARMd, Chong CL. Chemical and physical characteristics of cocoa butter substitutes, milk fat and Malaysian cocoa butter blends. J Am Oil Chem Soc 1998; 75: 8.

[19] Afoakwa EO, Paterson A, Fowler M, Vieira J. Influence of tempering and fat crystallization behaviours on microstructural and melting properties in dark chocolate systems. Food Res Int 2009; 42: 200-9.

[20] Tan YN. Bacteriostatic Mode of Action of Trypsin-Hydrolyzed Palm Kernel Expeller Peptide Against Bacillus cereus. Probiotics Antimicrob Proteins 2012; 4(1) : 59-65.

[21] Malaysia, Malaysian Food Regulations 1985. In: Malaysian Food Act 1983 (281 ACT).

[22] Servais C, Ranc H, Robertsi D. Determination of chocolate viscosity. J Tex Stud 2003; 34(5-6): 467-97.

[23] Romoscanu A. High frequency rheology of emulsions. ETH Zurich, Switzerland. 2003.

[24] Bouzas J, Brown BD. Interactions affecting microstructure texture and rheology of chocolate confectionery products. Ingredient interactions: Eff Food Quality 1995; 451-528.

[25] Sabariha Samsudin. Use of Palm Mid-Fraction in White Chocolate Formulation. J Sci Food Agri 1996; 71(4): 483-90.

[26] Talbot G. Fat eutetics and crystallization. In: S.T. Beckett, Ed. Physico-Chemical Aspects of Food Processing, London. Blackie Academic and Professional 1995; pp. 142-6.

[27] DerWeeën PV, De Clercq N, Baetens JM, Delbaere C, Dewenttinck K, De Baets B. A discrete stochastic model for oil migration in chocolate-coated confectionery. J Food Eng 2013; 119 (3): 602-10.

[28] Hartel RW. Chocolate: Fat bloom during storage. The influence of structural elements. Manuf Confec 1999; 79(5): 88-8.

[29] Schenk H, Peschar R. Understanding the structure of chocolate. Rad Phys Chem 2004; 71: 829-35.

[30] Hui YH. Handbook of Food Science Technology and Engineering. Vol 4. New York: CRC Press 2006.

[31] Franke K, Heinzelmann K, Tscheuschner HD. Structure Related Process Design in Chocolate Mass Manufacturing. In: Symposium Food Factory of the Future eds.; 2001: Gothenburg, Sweeden.

CC Saidin et al.; Licensee Bentham Open.

This is an open access article licensed under the terms of the Creative Commons Attribution Non-Commercial License (http://creativecommons.org/licenses/ by-nc/3.0/) which permits unrestricted, non-commercial use, distribution and reproduction in any medium, provided the work is properly cited. 